DOI: $10.21554 / \mathrm{hrr} .091903$

\title{
THE IMPACT OF GEOMETRY KNOWLEDGE ON THE ORIENTATION AND MOBILITY OF BLIND STUDENTS
}

\author{
Amela Teskeredžić ${ }^{1}$

\section{Hurma Begić Jahić}

Original scientific paper

Faculty of Education and Rehabilitation, University of Tuzla, Bosnia and Herzegovina

Received: 2019/6/24

Accepted: 2019/8/15

\begin{abstract}
The problem of blindness and other visual impairment is very important because it affects millions of people in the world. For those suffering from innate visual impairment, it is very difficult to imagine the world like it is, the fight begins from early school stages and continues until the end of life. This paper describes how the learning of basic geometric shapes, and their different positions, has an impact on the formation of a mental scheme in orientation and mobility. Geometry and its knowledge represent only one small part necessary for a safer and more independent movement of blind people. The research has shown that the quarterly individual work, on the adoption of geometric concepts and positions in students, is making progress in overcoming the recent problems. Spatial visualization implies understanding and imaginary movements, which, with spatial orientation and recognition of parts and relationships in the micro and macro environment, require mental rotation in relation to the position of the body. Therefore, it all together influences the formation of the mental scheme of the blind people, which is the basis for orientation and movement.

Keywords: geometry, orientation, mobility, blind students

\section{INTRODUCTION}

Geometric shapes (rectangles, triangles, squares, etc.) can be considered as categories that share common properties, which include an infinite number of specific shapes (Piaget \& Inhelder, 1947). Geometry is the main theory of space and the foundation of mathematics, a subject that students cannot avoid during their (school) life (Erwin et al., 2001). Studies have pointed out the importance of awareness of geometry (Edwards et al.,

2006), because it is not limited only to school subjects, but to everyday processes. This is crucial for people with visual impairment; to develop the correct sense of space, relationships and reasoning. It establishes the basis for systematic thinking through the numerical and spatial aspects of the objects. Proper process and manipulation of various objects in the space, together with the necessary spatial thinking, provides a strong background for other more advanced modules, such as trigonometry (Klatzky \& Lederman, 2003).
\end{abstract}

\footnotetext{
${ }^{1}$ Correspondence to:

Amela Teskeredžić, PhD, Faculty of Education and Rehabilitation, University of Tuzla, Bosnia and Herzegovina

Univerzitetska 1, 75000 Tuzla, Bosnia and Herzegovina

Phone:+38761 195865

E-mail: amela.teskeredzic@untz.ba; hurma.begic@untz.ba
} 
Although adults and children are able to categorize geometric shapes in some conditions, according to abstract geometric rules, they show prejudices against prototype forms, both in perception (the estimation of the typicality of the visualized triangles and quadrangles), as well as in the production tasks (drawing numbers) of different copies of the category (Feldman, 2000). The types of forms have become scattered structures organized around prototypes (Feldman, 2000; Medin \& Schaffer, 1978; Nosofsky, 1988; Rosch, 1975; Rosch \& Mervis, 1975), with whom blind students are usually acquainted with tactile perception, and their learning takes place by using the analytical way and synthetic way. An analytical way involves the individual perception of details and individual parts, and on the basis of these data an image of the object and its purpose is created. Synthetic way means the capture of the whole object by touching without details, and on the basis of the overall impression the object is recognized. In practice, both are complemented and used almost simultaneously. The important thing is that for the recognition through tactile perception it takes far more time than through visual perception (which is always complete). Partially-sighted students, for the perception of the environment, other than the rest of the senses, use the rest of the sight, but they also need more time (Matok, 2003). Perception generally has an object character, and it is oriented to objects and phenomena, and selective character, because it separates objects as forms from the background. Touch and other skin sensations are an important part of information about the outside world (Bosnar-Salihagić, 2011, according to Stančić, 1991). For blind people to orientate and move in space, knowledge of geometry and knowledge of basic shapes, relationships and angles are necessary. Haptic way, i.e. a method that supports tactile and kinesthetic sense has been studied to a limited extent since neurological and neuro-psychological research has shown that visual and haptic images of the brain are so similar that they can be in mutual modalities (James et al., 2002; Reales \& Ballesteros, 1999; Gaissert, Wallraven \& Bulthoff, 2010). Another powerful impetus to use haptics is that active learning is more effective than passive learning, i.e. the power of touch recognition is more powerful than simple observation (Hahm et al., 2007). For the purpose of discussing the perception of the blind people, it is best to talk about the mapping of data or their binding (visual, haptic...) or their combination (Foley \& Ribarsky, 1994), and user information, by combining these modes of operation as inputs and outputs, is defined as multi-modal joining (Oviatt, 1999). Nowadays, a number of software tools have been developed to learn geometry (Kaufmann \& Schmalstieg, 2003). More authors (Cesarek, 2014, according to Anthony et al., 2002; Hill, Rosen, Correa, \& Langley, 1984; Eichfield, 2011; Filan, 1998; Bishop, 1991; Anthony, 2014), point out that for the beginning of orientation and mobility for the child, the acquisition of different skills is important (perception-sensory skills, concept development, development of motor skills, assigned movement, tracing, use of protective skills, did he/ she use them before rods, etc.). Because learning about orientation and movement consists of training in motor skills, movements, sensory abilities, spatial concepts, tracing and protection techniques too (Cesarek, 2014). According to Kuyk et al. (2004), the above-mentioned skills are based on techniques that best utilize information obtained from possible residual vision and other sensory systems, as well as the techniques of using different aids (white cane, a human guide, a guide-dog and electronic aids). Orientation and movement is one of the important specific rehabilitation programs created for people with visual impairment (Fajdetić, 2012, according to De l'Aune, 2006), which, with the application of the correct methodology, results in the skills of safe, independent and oriented movement (Fajdetić, Zimmerman, \& Roman, 2006). The central role in planning and preparing the individualization of the treatment is to identify the individual specificities of students, which determine their success in solving the assigned tasks, as well as achieving an adequate educational achievement (Jablan et al., 2010). Findings of researchers suggest that blind and partially-sighted students use the same performance patterns, which shows that both groups use similar mental representations (Heller et al., 2005). According to Fleming (2010), most perceptual data, used by blind people, have been received and processed consecutively (for example, haptic and audio information), while visual data is received and processed in parallel. Therefore, Aleman et al. (2001) conclude that these shortcomings can occur due to serial processing of sound and touch, which can be slower and more susceptible to errors and parallel processing. When it comes to concepts about space and the environment, then it is asked from a blind person to have a clear and functional idea about three-dimensional objects, about their surfaces and shapes, and about the configuration of the environment, for example, about the plan of crossing streets, neighborhoods, layout of buildings, etc. 
Due to inappropriate reception of sensitive information and problems of environmental observation, blind people synthesize the collected information harder, and are not sufficiently using the adopted terms. The negative role in this problem may also belong to the parents' hesitation to allow the blind child to independently and self-explicitly investigate the environment and thus reducing the child's chances of adopting correct concepts about the environment (Zovko, 1994). Unfortunately, most teachers have very limited or insufficient experience in teaching students with visual impairment and it results with stereotypical views on what the blind students are capable of learning (Ballesteros et al., 2005). For blind and partially-sighted children, many factors influence the quality of orientation and movement skills: the quantity / quality of the visual remnants, whether the vision will remain the same, will be better or worse, is there more damage (auditory, motor, tactile, taste and smell) and many other factors. Prior to the training of orientation and movement, the instructor assesses the child's skills and abilities, and then based on the results, prepares the program of work. Therefore, the way to solve specific situations and exercises should be tailored to the individual, giving him/her the opportunity to learn and gradually study in the process of moving independently and responsibly to make decisions, and bear the consequences. Staging exercises based on their difficulty implies the separation of different stages, i.e. the components, their individual explanation, and ultimately the performance (Zovko, 1994). The planned individual program of orientation and movement is part of a complete program of rehabilitation of blind and visually impaired people (Runjić et al., 2009). The aim of the paper was to examine whether there is a difference in mastering the geometric concepts of blind students before and after the implementation of quarterly individual treatment in orientation and movement.

\section{METHODS}

The sample consisted of 30 blind students aged 7 to 15 , out of which 17 male and 13 female students, with the basic sampling for the sample being amourosis without any further damage. The research was carried out at the Center for children and youth with developmental disabilities "Budućnost" in Derventa (8 students) and the Center for blind and partiallysighted children and youth in Sarajevo (22 students). For data collection, data from the respondent's dossier - consisting of the basic data of the respondent - was used. The research applied the "Mobility Assessment Tool for the Blind" (Zovko, 1994), which established the initial and final levels of development of mobility capabilities of blind students. The test consists of ten sub-tests with a total of 67 variables. In this research, a sub-test Geometry was used which had tasks of recognizing certain shapes (cube, cylinder, square, circle, triangle, rectangle, pyramid, cuboid); placing a stick in a horizontal, vertical and parallel position, and turning the own body at 90 and 180 degrees, on the left and right sides. The scoring was performed in a manner that the done task was correct (T-2 points) and uncompleted or incorrect (N-1 point). After individually determining the initial level of development of perceptual abilities and mobility of blind students, individual quarterly treatments in the field of geometry have been prepared and applied, and which have direct influence on the orientation and mobility treatments. Because boarding school students were examined, the research was done after regular classes, in the student's free time. Individual treatments were done once a week with each student for 45 minutes. All individual treatments were in accordance with established safety rules and with the verbalization of the ongoing activities. One trial exercise was permitted, in order to gain a sense of the task to be performed, and after that the students independently did their exercises/tasks. After the individual treatment of orientation and mobility, using the same test, a final assessment of geometric knowledge was carried out in order to determine the level and impact of the same on the orientation and mobility of blind students. For statistical data processing, descriptive statistic methods were used, and a t-test for the dependent sample of the respondents was used to examine the significance of the differences between the arithmetic meanings of the initial and final states. The research was carried out with a level of significance of $5 \%(.05)$.

\section{RESULTS AND DISCUSSION}

The importance of mathematics as well as the mastering of geometric concepts is not only reflected in mastering basic mathematical operations, developing the ability to solve logical problems, but it also plays an important role in the orientation and mobility of blind students. In mathematics and geometry, a number of mathematical models are used in which blind students, using the tactile way, create a representation of the three-dimensional shape and position of objects in the space, and therefore the (space) relation of their body to another. 
Based on the evaluation carried out (Kouba, Ovadia, \& Brill, 1990), students fail to understand the basic concepts of geometry and fail to master the skills of solving geometric problems. Factors that lead to this poor achievement are the habit and practice of students who focus only on identifying and naming geometric shapes and learning symbols for basic concepts of geometry (Daneman \& Carpenter, 1980). The results obtained in relation to the geometry of the initial measurement on the variable "Geometry1" referring to the recognition of individual shapes (cube, cylinder, square, circle, triangle, rectangle, pyramid, cuboid) show that the mean is $14.70 \pm 1.93$, median and mode 16 , while the minimum and maximum results range from 10 to
16 (Table 1). In relation to symmetry measures, the distribution is negatively asymmetrical (.63) and platykurtical (-.63). The mean of the variable "Geometry2" referring to the orientation with the object in the horizontal, vertical and parallel position is $3.67 \pm .76$, median and mode are 4 , the minimum and maximum results range from 2 to 4 . Distribution is negatively asymmetrical (-1.88) and platykurtical (1.66). The mean of the variable "Geometry3" referring to the rotation of one's own body at certain angles and sides is $5.20 \pm 1.86$, median and mode are 4 and the minimum and maximum results range from 4 to 8 (Table 1). The results in relation to symmetrical and kurtosis measures show that distribution is asymmetric and platykurtic.

Table 1. Measures of central tendency and dispersion measures in relation to observed variables (initial measurement)

\begin{tabular}{lccccccccc}
\hline Variables & Mean & $\mathbf{M}_{\mathbf{d}}$ & $\mathbf{M}_{\mathbf{0}}$ & $\mathbf{S D}$ & $\mathbf{V a r}$ & $\mathbf{S}_{\mathbf{k}}$ & $\mathbf{K}_{\mathbf{u}}$ & $\mathbf{M i n}$ & $\mathbf{M a x}$ \\
\hline Geometry1 & 14.70 & 16.00 & 16.00 & 1.93 & 3.73 & -.99 & -.63 & 10.00 & 16.00 \\
\cline { 2 - 9 } Geometry2 & 3.67 & 4.00 & 4.00 & .76 & .57 & -1.88 & 1.66 & 2.00 & 4.00 \\
Geometry3 & 5.20 & 4.00 & 4.00 & 1.86 & 3.48 & .92 & -1.24 & 4.00 & 8.00 \\
\hline
\end{tabular}

Legend: Geometry1 - shape/form recognition; Geometry2 - orientation with the object in a horizontal and vertical position; Geometry 3 - rotation of one's own body at certain angles and sides

The results of the final measurement (Table 2) obtained on the "Geometry1" variable indicate that the mean is $15.67 \pm .96$, the median and the mode are 16 , while the minimum and maximum results range from 12 to 16 . In relation to symmetry measures, the distribution is negatively asymmetric (-3.03) and leptokurtic (8.68) (Table 2). The mean of the variable "Geometry2" is $3.80 \pm .61$, median and mode are 4, the minimum and maximum results range from 2 to 4. Distribution is negatively asymmetric (-2.81) and leptokurtic (6.31). The mean of the variable "Geometry3" is $6.80 \pm 1.86$, median and mode are 8 , and the minimum and maximum results range from 4 to 8 . The results in relation to symmetrical and kurtosis measures show that the distribution is negatively asymmetric and platykurtic.

Table 2. Measures of central tendency and dispersion measures in relation to observed variables (initial measurement)

\begin{tabular}{lccccccccc}
\hline Variables & Mean & $\mathbf{M}_{\mathbf{d}}$ & $\mathbf{M}_{\mathbf{0}}$ & SD & Var & $\mathbf{S}_{\mathbf{k}}$ & $\mathbf{K}_{\mathbf{u}}$ & $\mathbf{M i n}^{\mathbf{M a x}}$ \\
\hline Geometry1 & 15.67 & 16.00 & 16.00 & .96 & .92 & -3.03 & 8.68 & 12.00 & 16.00 \\
Geometry2 & 3.80 & 4.00 & 4.00 & .61 & .37 & -2.81 & 6.31 & 2.00 \\
Geometry3 & 6.80 & 8.00 & 8.00 & 1.86 & 3.48 & -.92 & -1.24 & 4.00 & 8.00 \\
\hline
\end{tabular}

Legend: Geometry1 - shape/form recognition; Geometry2 - orientation with the object in a horizontal and vertical position; Geometry3 - rotation of one's own body at certain angles and sides

Based on the results obtained in Table 3, it can be concluded that there is no difference between the initial and the final measurement, i.e. before and after the treatment on the variable "Geometry2" $(\mathrm{t}=-1.43 ; \mathrm{p}=$ $.16)$, and which refers to orientation in the horizontal and vertical position. On the variables "Geometry1" $(\mathrm{t}$ $=-3.43 ; \mathrm{p}=.00)$ and "Geometry3" $(\mathrm{t}=-4.39 ; \mathrm{p}=.00)$, t-test results showed that there was a statistically significant difference and these differences are in favor of the final measurement. 
Table 3. T-test results in relation to geometry

\begin{tabular}{|c|c|c|c|c|c|}
\hline Orientation & Measurement & Mean & SD & $t$ & $p$ \\
\hline \multirow[t]{2}{*}{ Geometry1 } & Initial & 14.70 & 1.93 & \multirow{2}{*}{-3.43} & \multirow{2}{*}{.00} \\
\hline & Final & 15.67 & .96 & & \\
\hline \multirow[t]{2}{*}{ Geometry2 } & Initial & 3.67 & .76 & \multirow{2}{*}{-1.43} & \multirow{2}{*}{.16} \\
\hline & Final & 3.80 & .61 & & \\
\hline \multirow[t]{2}{*}{ Geometry3 } & Initial & 5.20 & 1.86 & \multirow{2}{*}{-4.39} & \multirow{2}{*}{.00} \\
\hline & Final & 6.80 & 1.86 & & \\
\hline
\end{tabular}

Legend: Geometry1 - shape/form recognition; Geometry 2 - orientation with the object in a horizontal and vertical position; Geometry3 - rotation of one's own body at certain angles and sides

During our initial assessment, younger students did not demonstrate a good knowledge of geometric bodies figures, because they had not yet been introduced to mathematics. They were mostly familiar with shapes such as cubes, circles, cylinders (most commonly used in the child's play), while the concepts of the pyramid, cone, rectangle, cuboid and square caused confusion among students. They did not do well in the tasks of placing objects at a certain position (horizontally, vertically, in parallel). After a three-month individual work on the adoption of geometric concepts and positions, individual students showed progress in overcoming recent problems. Older students have mostly done this part of the test well because of their already existing knowledge about geometric concepts. We are already aware that "visual-spatial mental images" refer to certain types of mental representations that result from a complex cognitive process, which depend on different sources of information. Furthermore, this information is processed within the framework of the "visual-spatial active memory" (Klingenberg, 2007), which extracts specific information about an object that is not completely identical to the original one. These specific information acts as a reference to mental models of objects that are easily "extracted from memory" when it is needed to represent or identify a particular object. Blind people can develop mental images, but they are organized in a different way from the mental images of people without visual impairment, which again depends on the perceptual and collected haptic experience of the person (Bouaziz et al., 2005; Cornoldi et al., 2003). Gentaz et al. (Pinet \& Gentaz, 2007; Pinet \& Gentaz, 2008; Kalénine, Pinet, $\&$ Gentaz, 2010), generalizing the results of the research, showed that, at the age of 5 , the recognition of rectangles or triangles is better in relation to some other particular forms and shapes. The results have shown that in adults and children, both in perception and in the domain of reproduction, the categories of forms and shapes usually have stepped structures organized around a prototype, in which horizontal orientation plays an important role in their definition.

Geometry is one of the most difficult subjects for blind students to master, but at the same time one area of which they have a lot of benefits when forming their mental maps. The classical learning of geometry is based on visual modalities (drawings, charts, lines, curves, etc.), which is not available to blind people. The study of Solene, Pinet and Gentaz (2011), was intended to examine the benefits of multi-sensory interventions in recognizing geometric shapes in the kindergarten. An experiment was performed in which a visual and haptic modality was examined in one group of children, and in the second group, only a visual modality, on a total of 72 pre-school children. The results showed that children have made more progress using both visual and haptic modality, compared to the use of only visual modality (rectangle and triangle). The authors believe that the addition of haptic modality in intervention provides useful effects by allowing children to better understand what is included in the category of forms/shapes.

Zovko (1994) conducted a case study on two students of the eighth grade of the "Vinko Bek Primary School" in Zagreb, where he tried to evaluate the impact of systemic exercises on improving the ability of visually impaired people to orientate and move. An individual treatment was conducted twice a week from 14:00 to $16: 00$ o'clock in a period of about three months. During the examination of the distinction between plane figures (geometric shapes) and solid figures, both students showed knowledge of the distinction between plane figures, while they were less familiar with solid figures. They independently identified the cube, the ball and the cylinder, but they sought help in identifying and naming the cuboid, cone and pyramid. Difficulties are evident in the mix up of the cuboid and the cube. 
This misconception is eliminated by indicating the essential differences between the mentioned solid figures.

In his study of the tactile observation of the permanence of the shape/form, Worchel (1951) found that blind children were at the same level as children without visual impairment. However, they have succeeded poorly in tasks of spatial relations and spatial orientation. In his experiments, Hatwell (1985) finds that, in the tasks of perception of the form/shape, blind children achieve less success than children without visual impairment and that children without visual impairment are better in this perception due to early learning, which comes to them spontaneously. Observation of the form/shape is in significant correlation with learning, experience and other internal factors of observation (Jablan, 2007).

The work of Rouzier et al. (2004) describes a touchand-sound system to help understand the concepts of geometry for blind students, and more information is obtained from experiments conducted at a school for blind children. This system enables tactile reading, measurement and the making of geometric figures. This system can help blind students form a mental representation of geometric and topological concepts. Ungar et al. (1995) conducted a survey on the method and importance of adopting a tactile map for blind and partially-sighted students. The study included 24 children with visual impairment and 22 short-sighted children, aged 7 to 13 . Children had to learn tactile maps and reconstruct them from memory. Here, the strategy of learning was observed, which children use to remember tactile maps. All activities were verbalized by children. The authors came to the conclusion that reconstruction by children with visual impairment is less accurate than those of short-sighted children. It has also been found that most children with visual impairment use strategies that are unsuitable for the task. The results of several authors (Kalénine, Cheam, Izard, \& Gentaz, 2013; Pinet \& Gentaz, 2008; Pinet \& Gentaz, 2007; Kalénine, Pinet, \& Gentaz, 2010) have shown that in adults and children both in perception and in the domain of reproduction, the form/shape categories usually have stepped structures arranged around a prototype, in which horizontal orientation plays an important role in defining them.

\section{CONCLUSION}

The results of different estimates reveal that blind students fail to learn basic geometric concepts, in particular the solving of geometric problems. The research has shown that a quarterly individual treatment, which relates to the adoption of geometric concepts and their position in space, has resulted in progress in mastering tasks previously set before blind students. In regular schools, the traditional approach is still used to learn geometry, without taking into account the ability to generate data and concrete thinking, and the visualization of the same. Spatial abilities and mathematical achievements are linked, and the spatial reasoning of geometry is therefore the basis for orientation and mobility together with spatial visualization. Spatial visualization implies understanding of imaginary movements, which, with spatial orientation and recognition of parts and relationships in the micro and macro environment, requires mental rotation in relation to the position of the body. Therefore, it all together influences the formation of the mental scheme of blind people, which is the basis for orientation and movement.

\section{REFERENCES}

Anthony, J.L., Lonigan, C.J., Burgess, S.R., Driscoll, K., Phillips, B.M., \& Cantor, B.G. (2002). Structure of preschool phonological sensitivity: Overlapping sensitivity to rhyme, words, syllables, and phonemes. Journal of Experimental Child Psychology, 82, 65-92.

Anthony, T. (2014). Orientation And Mobility (O\&M): The Early Years Of Infancy Through Preschool. Retrieved from http://www.tsbvi.edu/orientation-amobility/3228-orientation-and-mobility-oam-the-early-years-of-infancythroughpreschool.

Aleman, A., Van Lee, L., Mantione, M., Verloijen, I., \& de Haan, E. (2001). Visual Imagery without visual experience: Evidence from congenitally totally blind people. Neuroreport, 12(11), 2601-2604.

Ballesteros, S., Bardisa, D., Millar, S., \& Reales, J. (2005). The haptic test battery: A new instrument to test tactual abilities in blind and visually impaired and sighted children. The British Journal of Visual Impairement, 23(1), 11-24.

Bouaziz, S., Russier, S., \& Magnan, A. (2005). The Copying of Complex Geometric Drawings by Sighted and Visually Impaired Children. Journal of Visual Impairement and Blindness, 99(12), 765-774.

Cornoldi, C., Fastame, M., \& Vecchi, T. (2003). Congenitally blindness and spatial mental imagery. In a. Hatwell Y., \& a. V. Streri A., Congenitally blindness and spatial mental imagery (pp. 173-187). Amsterdam/Philadelphia: John Benjamins Publishing Company.

Češarek, S. (2014). Predvaje za orientacijo in mobilnost predšolskih otrok. http://www.kss-ess.si/wp-content/ uploads/2014/03/Predvaje-za-orientacijo-in-mobilnostpred\%C5\%A1olskih-otrok.pdf.

Daneman, M., \& Cerpenter, P.A. (1980). Individual differences in working memory and reading. Journal of Verbal Learning and Verbal Behavior, 19, 450-466. 
Eichfeld, J. (2011). About Pre-cane Skills: What are Pre-cane Skills and How Can I Help? Retrieved from http://adifferentkindofvision.blogspot.com/2011/02/about-pre-caneskills.html.

Erwin, E., Perkins, T., Ayala, J., Fine, M., \& Rubin, E. (2001). You don't have to be sighted to be a Scientiest, Do you? Issues and Outcomes in Science Education. Journal of Visual Impairment and Blindness, 95(6), 338-352.

Edwards, A., McCartney, H., \& Fogarolo, F. (2006). Lambda a multimodal approach to making mathematics accessible to blind students. Proceedings of the 8th international ACM SIGACCESS conference on Computers and accessibility. ISBN: 1- 59593-290-9. New York City: ACM New York, NY, USA C2006. doi:10.1145/1168987.1168997.

Fajdetić, A. (2012). Slijepi učenici i usvajanje jezika u integriranom odgoju i obrazovanju. Časopis za pedagogijsku teoriju i praksu, 153(3-4), 463-482.

Feldman, J. (2000). Bias toward regular form in mental shape spaces. Journal of Experimental Psychology: Human Perception \& Performance, 26, 152-165.

Filan, S. (1998). Orientation and Mobility. V E. Trief(ed.), Working With Visually Impaired Young Students: A Curriculum Guide For 3 to 5 Year Olds, 81-96. U.S.A.: Charles C Thomas.

Fleming, P., Ball, L., Collins, A., \& Ormerod, T. C. (2010). Spatial Representation and Processing in the Congenitally Blind. In S. Ballesteros, \& M. Heller, Touch, blindness, and neuroscience. Madrid, Spain: UNED Press.

Foley, J., \& Ribarsky, B.: Next-generation data visualization tools. In: Rosenblum, L., Earnshaw, R.A., Encarnacao, J., Hagen, H., Kaufman, A., Klimenko, S., Nielson, G., F. Post, \& Thalmann, D. (1994). (eds.) Scientific Visualization, Advances and Challenges. Academic Press, Waltham.

Gaissert, N., Wallraven, C., \& Bulthoff, H.H. (2010). Visual and haptic perceptual spaces show high similarity in humans. Journal of Vision, 10(11:2), 1-20.

Hahm, J., Lee, K., Lim, S.-L., Kim, S.-Y., Kim, H.-T., \& Lee, J.-H. (2007). Effects of Active Navigation on Object Recognition in Virtual Environments, Cyber Psychology and Behaviour, 10, 305-308. Mary Ann Liebert, Inc., New York.

Hatwell, Y. (1978). Form perception and related issues in blind humans. In Held R, Leibowitz HW, \& Teuber HL, editors. Handbook of sensory physiology, VII: Perception. New York and Berlin: Springer Verlag.

Hill, E. W., Rosen, S., Correa, V. I., \& Langley, M. B. (1984). Preschool orientation and mobility: An expanded definition. Education of the Visually Handicapped, 16(2), 5872.

Jablan, B. (2007). Motorne i taktilne funkcije kod slepe dece, Fakultet za specijalnu edukaciju $i$ rehabilitaciju. Beograd: Centar za izdavačku djelatnost.

Jablan, B., Kovačević, J., \& Teskeredžić, A. (2010). Didaktičko modelovanje nastave matematike $\mathrm{u}$ radu sa djecom ometenom u razvoju. Specijalna edukacija i rehabilitacija, 9(1), 111-124.

James, T.W., Humphrey, G.K., Gati, J.S., Servos, P., Menon, R.S., \& Goodale, M.A. (2002). Haptic study of threedimensional objects activates extra striate visual areas. Neuropsychologia 40, 1706-1714.
Kaufmann, H., \& Schmalstieg, D. (2003). Mathematics and geometry education with collaborative augmented reality. Computers \& Graphics 27(3), 339-345.

Kalénine, S., Pinet, L., \& Gentaz, E. (2010). The visual and visuo-haptic exploration of geometrical shapes increases their recognition in preschoolers. International Journal of Behavioral Development 35, 18-26.

Kalénine, S., Cheam, C., Izard, V., \& Gentaz, E. (2013). Adults and five year-old children draw rectangles and triangles around a prototype but not in the golden ratio, British Journal of Psychology, 104 (3), 400-412.

Klatzky, R., \& Lederman, S. (2003). The haptic identification of everyday life objects. In Y. Hatwell, A. Streri, \& E. Gentaz, Touching for knowing: cognitive psychology of haptic manual perception, 53, 105-121.

Kuyk, T., Elliott, JL., Wesley, J., Scilley, K., McIntosh, E., Mitchell, S., \& Owsley, C. (2004). Mobility function in older veterans improves after blind rehabilitation. $J$ Rehabil Res Dev, 41, 337-346.

Kouba, Gene E., Ovadia, S., \& Brill, J. (1990). A nonintrusive flowmetering method for two-phase intermittent flow in horizontal pipes. SPE Production Engineering, 5(4): 373-380.

Klingenberg, G. (2007). Geometry: Educational Implications for Children with Visual Impairment. Norwegian University of Science and Technology.

Medin, D., \& Schaffer, M. (1978). Context model of classification learning, Psychological Review, 85(3), 207-238.

Matok, D. (2003). Integracija učenika s oštećenjem vida. Centar za odgoj i obrazovanje „Vinko Bek“, Zagreb. Retrieved from http://www.savez-slijepih.hr/hr/kategorija/integracija-ucenika-ostecenjem-vida-458/.

Nosofsky, R. M. (1988). Similarity, frequency, and category representations. Journal of Experimental Psychology: Learning, Memory, and Cognition, 14(1),54-65.

Oviatt, S. (1999). Ten myths of myths of multimodal interaction. Commun. ACM, 42(11), 74-81.

Piaget, J., \& Inhelder, B. (1947). La représentation de l'espace chez l'enfant. Paris: PUF.

Pinet, L., \& Gentaz, E. (2007). La reconnaissance des figures géométriques planes par les enfants de 5 ans. Grand $N$, $80,17-24$.

Pinet, L., \& Gentaz, E. (2008). Évaluation d'entraînements multisensoriels de préparation à la reconnaissance de figures géométriques planes chez les enfants de 5 ans: Etude de la contribution du système haptique manuel. Revue Française de Pédagogie, 162, 1-20.

Rosch, E. (1975). Cognitive reference points. Cognitive Psychology 7, 532-547.

Rosch, E., \& Mervis, CB. (1975). Family resemblances: Studies in the internal structure of categories. Cognitive Psychology 7, 573-605.

Runjić, T., Nikolić, B., \& Bilić Prcić, A. (2009). Povezanost tehnika videčeg vodića i samostalnog kretanja osoba oštećena vida. Hrvatska revija za rehabilitacijska istraživanja, 45(2), 1-10.

Rouzier, S., Hennion, B., Segovia, T.P., \& Chene, D. (2004). Touching geometry for visually impaired pupils. Proceedings of EuroHaptics, Munich Germany, 697-704. 
Reales, J.M., \& Ballesteros, S. (1999). Implicit and explicit memory for visual and haptic objects: cross-modal priming depends on structural descriptions. Journal of Experimental Psychology: Learning, Memory, and Cognition, 25(3), 644-663.

Stančić, V. (1991). Oštećenja vida-Biopsihosocijalni aspekti. Zagreb: Školska knjiga.

Solene, K., Pinet, L., \& Gentaz, E. (2011). The visual and visuohaptic exploration of geometrical shapes increases their recognition in preschoolers. International Journal of Behavioral Development, 35(1), 18-26.
Ungar, S., Blades, M., \& Spencer, C. (1995). Mental rotation of a tactile layout by young visually impaired children. Perception, 24(8), 891-900.

Worchel, P. (1951). Space perception and orientation in the blind. Psychological Monographs: General and Applied, 65(15), i-28.

Zovko, G. (1994). Utjecaj vježbanja na usvajanje pojma o vlastitom tijelu. Defektologija, 30(2), 95-103.

Zovko, G. (1994). Peripatologija 1. Zagreb: Školske novine. 